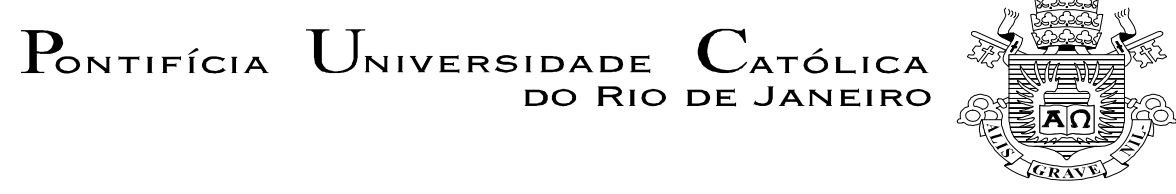

Elaine Souza da Silva

A construção de identidades no discurso

de professores, alunos e direção

de uma instituição pública

de educação básica

Dissertação de Mestrado

Dissertação apresentada ao Programa de Pós-graduação em Letras da PUC-Rio como requisito parcial para obtenção do título de Mestre em Letras.

Orientadora: Profa. Dra. Tânia Mara Gastão Saliés 


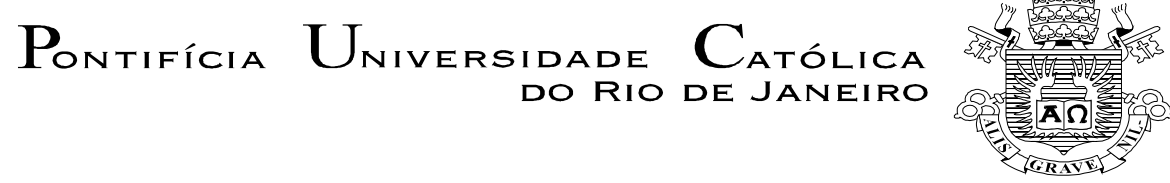

Elaine Souza da Silva

\section{A construção de identidades no discurso \\ de professores, alunos e direção \\ de uma instituição pública \\ de educação básica}

Dissertação apresentada como requisito parcial para obtenção do grau de Mestre pelo Programa de PósGraduação em Letras do Departamento de Letras do Centro de Teologia e Ciências Humanas da PUC-Rio. Aprovada pela Comissão Examinadora abaixo assinada.

Profa. Tânia Mara Gastão Saliés

Orientadora

Departamento de Letras PUC-Rio

Profa. Anna Elizabeth Balloco

UERJ

Profa. Inés Kayon de Miller Departamento de Letras - PUC-Rio

Profa. Edna Campos Pacheco-Fernandes

PUC-Rio

Prof. Paulo Fernando Carneiro de Andrade

Coordenador Setorial do Centro de Teologia

e Ciências Humanas - Puc-Rio

Rio de Janeiro, sete de março de 2006. 
Todos os direitos reservados. É proibida a reprodução total ou parcial do trabalho sem autorização do autor, do orientador e da universidade.

\section{Elaine Souza da Silva}

Graduou-se em Português-Latim na Universidade Federal do Rio de Janeiro em 1995. Especializou-se em Marketing na Universidade Cândido Mendes em 1998. Cursou Pós-graduação Stricto Sensu em Estudos da Linguagem na Pontifícia Universidade Católica do Rio de Janeiro em 2006. É professora de Língua Portuguesa da Secretaria Estadual de Educação do Rio de Janeiro e da Fundação de Apoio às Escolas Técnicas - Rede Faetec. Leciona Língua Portuguesa e Produção de Texto, como professora substituta, no Instituto de Letras da Universidade do Estado do Rio de Janeiro.

Ficha Catalográfica

Silva, Elaine Souza da

A construção de identidades no discurso de professores, alunos e direção de uma instituição pública de educação básica / Elaine Souza da Silva ; orientadora: Tânia Mara Gastão Saliés. - Rio de Janeiro : PUC, Departamento de Letras, 2006.

119 f. : il. ; $30 \mathrm{~cm}$

Dissertação (mestrado) - Pontifícia Universidade Católica do Rio de Janeiro, Departamento de Letras.

Inclui referências bibliográficas.

1. Letras - Teses. 2. Identidades discursivas. 3. Sistema de transitividade. 4. Modalidade. 5. Discurso. I.Saliés, Tânia Mara Gastão. II. Pontifícia Universidade Católica do Rio de Janeiro. Departamento de Letras. III. Título. 
Ao meu esposo - meu porto seguro, meu conforto e amparo, amor meu,

Aos meus pais, pela vida e por acreditarem em mim,

Aos meus irmãos, pelo constante apoio,

Dedico meis parentibus amatis. 


\section{Agradecimentos}

A DEUS, por ter me propiciado essa oportunidade e pela Graça concedida nos momentos de atribulação;

À minha orientadora e amiga, Profa. Dra. Tânia Mara Gastão Saliés, pela dedicação, pelo companheirismo e pela colaboração para o meu crescimento pessoal e profissional;

Às Profas. Inés Miller, Anna Balloco e Edna Pacheco, pela participação na minha banca e por toda a colaboração;

À FAETEC, por ter concedido meus estudos;

Aos colegas participantes da pesquisa, sem os quais não conseguiria realizar o estudo;

À Chiquinha e aos demais funcionários do Departamento de Letras, pela amizade;

À Márcia Lopes, pelo apoio durante a pesquisa;

À amiga Aline da Silva, por todo o incentivo, pelas palavras certas nos momentos certos, pela amizade sincera e por ajudar-me na revisão gramatical;

Aos meus cunhados, sogros e sobrinho, por entenderem minha ausência;

A todos os familiares e amigos que me apoiaram e incentivaram;

Aos meus pais, pelo amor, carinho, pela força e dedicação nas horas mais difíceis;

E ao meu esposo, por me possibilitar luz na escuridão, pelo companheirismo de todas as horas e pela incansável dedicação. 


\section{RESUMO}

Silva, Elaine Souza da; Saliés, Tânia Mara Gastão. A construção de identidades no discurso de professores, alunos e direção de uma instituição pública de educação básica. Rio de Janeiro, 2006. 119 p. Dissertação de Mestrado - Departamento de Letras, Pontifícia Universidade Católica do Rio de Janeiro.

A construção de identidades no contexto educacional tem sido foco de muitos estudos contemporâneos (eg. Fairclough, 1995; Kumaravadivelu, 1999; Kleiman, 2001; Moita Lopes, 1999). Essas pesquisas evidenciam a interação entre professores e alunos como elemento primordial para a observação e análise das identidades projetadas discursivamente no processo ensino-aprendizagem dentro do contexto da sala de aula. No entanto, as identidades discursivas da direção não aparecem como objeto de estudo nesse contexto. O presente estudo preenche tal lacuna, investigando como professores, alunos e direção constroem discursivamente suas identidades em um contexto que não o de sala de aula. A investigação é realizada com base na microanálise etnográfica (Erickson, 1996) e os dados foram obtidos através de questionários, narrativas e prática exploratória, tendo sido analisados qualitativamente a partir do sistema de transitividade e da modalidade da Gramática Sistêmico-Funcional (Halliday, 1985, 1994), à luz de uma abordagem crítica do discurso pedagógico (Fairclough, 1995; Giroux, 1997). Os resultados sinalizam que, discursivamente, as identidades projetadas pela direção consolidam-se no discurso da administração e controle (Giroux, 1997) e corroboram o papel que a direção assume institucionalmente. Por outro lado, professores e alunos projetam identidades segundo o discurso da relevância e integração. Finalmente, os dados também apontam que o afeto é utilizado, implicitamente, como estratégia de negociação.

\section{Palavras-chave} discurso.

Identidades discursivas, sistema de transitividade, modalidade, análise de 


\section{ABSTRACT}

Silva, Elaine Souza da; Saliés, Tânia Mara Gastão. The construction of identities in the discourse of teachers, students and the school board in a public institution for basic education. Rio de Janeiro, 2006. 119 p. Dissertação de Mestrado - Departamento de Letras, Pontifícia Universidade Católica do Rio de Janeiro.

The construction of identities in educational contexts has been the focus of many contemporary studies (eg. Fairclough,1995; Kamaravadivelu,1999; Kleiman, 2001; Moita Lopes, 1999). Such research has focused on interaction between teachers and students, observing and analyzing discursive identities projected along the teaching-learning process, in a classroom context. However, the discursive identities projected by the school board do not emerge in this context. This study fulfills such a gap, investigating how teachers, students and the school board construct their discursive identities in a context other than the classroom. To do so, it conducts ethnographic microanalysis (Erickson,1996) on data obtained by questionnaires, narratives and exploratory practice, within a qualitative paradigm. The categories of analysis are from Systemic-Functional Grammar (Halliday, 1985 and 1994), namely the transitivity system and modality, and they have been undertaken from the critical perspective of pedagogical discourse analysis (Fairclough, 1995; Giroux, 1997). The results have indicated that the identity discursively projected by the school board fits the management and control discourse (Giroux,1997), corroborating the board's institutional role. On the other hand, teachers and students project identities that fit the relevance and integration discourse. In addition, results have revealed that affect is implicitly used as a negotiation strategy.

\section{Keywords}

Discursive identities, transitivity system, modality, discourse analysis. 


\section{SUMÁRIO}

1. Introdução 13

2. Revisão de literatura 16

2.1. Caminhos para uma análise crítica do discurso pedagógico 16

2.1.1. A Análise Crítica de Discurso na perspectiva de Fairclough 18

2.1.2. A Análise Crítica de Discurso na perspectiva de Kumaravadivelu 19

2.1.3. A Análise Crítica de Discurso na perspectiva de Giroux 21

2.1.3.1. O discurso da administração e controle 22

2.1.3.2. O discurso da relevância 23

2.1.3.3. O discurso da política cultural e a pedagogia crítica 24

2.2. Conceitos de identidades $\quad 25$

2.3. As narrativas e a construção de identidade $\quad 31$

2.4. A gramática sistêmico-funcional 33

2.4.1. O sistema de transitividade $\quad 35$

2.4.1.1. Processos materiais $\quad 37$

2.4.1.2. Processos mentais $\quad 37$

2.4.1.3. Processos relacionais 38

2.4.1.4. Processos verbais $\quad 39$

2.4.1.5. Processos comportamentais $\quad 39$

2.4.1.6. Processos existenciais $\quad 40$

2.4.2. Modalidade 41

2.5. Síntese do arcabouço teórico $\quad 42$

3. Metodologia 43

3.1. Natureza da pesquisa $\quad 43$

3.2. O contexto 44

3.2.1. A escola 45

3.2.2. Os participantes $\quad 46$

3.2.2.1. A direção $\quad 47$

3.2.2.2. A coordenação 48

3.2.2.3. Os alunos 48

3.2.2.4. Os professores 48

3.2.2.5. A pesquisadora 49

3.3. Objetivos $\quad 49$

3.3.1. Objetivo geral 49

3.3.2. Objetivos específicos 49

3.4. Constituição do banco de dados $\quad 50$

4. Análise e discussão dos dados $\quad 53$

4.1. Análise dos questionários $\quad 53$

4.1.1. As respostas de Renato e Bethânia 53

4.1.2. As respostas de Beth, a diretora $\quad 59$

4.1.3. As respostas de Flávio, Márcio e Pedro 61

4.2. Análise das narrativas 65

4.2.1. A narrativa de Beth, a diretora 66 
4.2.2. As narrativas de Flávio, Márcio e Pedro 71

4.2.3. As narrativas de Renato e Bethânia 79

4.3. Análise dos cartazes $\quad 87$

4.4. Triangulação dos dados

4.4.1. Ideologias presentes no discurso dos participantes 94

4.4.2. A construção das identidades discursivas dos participantes $\quad 95$

$\begin{array}{ll}\text { 4.4.3. Os tipos de discurso } & 95\end{array}$

5. Considerações finais 98

5.1. Contribuições do estudo 98

5.2. Questões e perspectivas abertas $\quad 99$

5.3. Recomendações para estudos futuros 99

6. Referências bibliográficas 101

Anexos

Anexo A-corpus: questionários $\quad 104$

Anexo B-corpus: transcrição dos dados 106 


\section{Lista de figuras}

1. Concepção tridimensional do discurso 18

2. Tipos de processos 36

3. Graus de modalidade 42

4. Composição do corpus 47

5. Visão dos alunos sobre o papel do professor na educação 64

6. Disposição face a face dos participantes 66

7. Visão de Renato sobre o processo educacional 83

8. Visão de Bethânia sobre o processo educacional 87

9. Cartaz elaborado por Renato, professor de História 88

10. Cartaz elaborado por Bethânia, professora de Língua Portuguesa 89

11. Cartaz elaborado por Beth, a diretora $\quad 89$

12. Cartaz elaborado por Márcio, aluno 90

13. Cartaz elaborado por Flávio, aluno 91

14. Cartaz elaborado por Pedro, aluno 92 


\section{Lista de tabelas}

1. Processos, significações e participantes 40

2. O questionário 51

3. A relação dos alunos com os professores 62

4. Ideologias, tipos de identidades e discurso 96 


\section{Convenções de transcrição}

\begin{tabular}{|c|c|}
\hline$\cdots$ & Pausa de meio ou de um segundo, não cronometrada. \\
\hline$\cdot$ & Descida leve sinalizando final do enunciado. \\
\hline$?$ & Subida rápida sinalizando uma interrogação. \\
\hline , & Subida leve, sinalizando que mais fala virá. \\
\hline-- & $\begin{array}{l}\text { Fragmentação da unidade entonacional antes da conclusão do contorno } \\
\text { entonacional projetado. }\end{array}$ \\
\hline- & Final projetado da palavra não enunciado. \\
\hline : ou :: & Alongamentos. \\
\hline MAIÚSCULA & Acento forte. \\
\hline--- & Silabação. \\
\hline Repetições & Reduplicação de letra ou sílaba. \\
\hline$(\quad)$ & Dúvidas, suposições, anotações do analista. \\
\hline$[$ ] & Sinalização da comunicação não-verbal. \\
\hline $\begin{array}{l}\text { eh, ah, oh, ih, } \\
\text { hum, ahã, } \\
\text { humhum }\end{array}$ & Pausa preenchida, hesitação ou sinais de atenção. \\
\hline$[[$ & Início do turno simultâneo. \\
\hline$[\quad]$ & Sobreposição de fala localizada. \\
\hline$=$ & Elocuções contíguas, enunciadas sem pausa entre elas. \\
\hline$(\ldots)$ & Supressão de fragmento transcrito. \\
\hline
\end{tabular}

